\title{
La complementariedad entre la deontología y el derecho a propósito de la actividad informativa
}

\author{
Juan Carlos SuÁRez Villegas \\ Universidad de Sevilla \\ jcsuarez@us.es
}

Recibido: $18 / 03 / 2012$

Aceptado: 28/09/2012

\begin{abstract}
Resumen
En el presente artículo se ahonda en las relaciones de continuidad entre las normas deontológicas que deben regir los principios de la profesión periodística y el marco normativo provisto por el Derecho para un ejercicio pleno y respetuoso con los bienes sociales inherentes a la propia profesión. Para ello, se postulará la pertinencia de una autorregulación impuesta y consensuada por todos los actores implicados en la práctica diaria del periodismo que se adecue a la defensa de otra serie de derechos de los ciudadanos recogidos en la Constitución con los que podría entran en confrontación.
\end{abstract}

Palabras clave: Periodismo-Deontología-Derecho-Autorregulación-Responsabilidad

\section{The Complementarity between Deontology and Law in Journalism}

\begin{abstract}
This article delves into the relationship of continuity between the ethical rules that should govern the principles of the journalistic profession and the regulatory framework provided by law for a full and respectful of social goods inherent in the profession. To do this, will run the relevance of a self-imposed and agreed by all parties involved in the daily practice of journalism that is appropriate to the defense of another series of rights of citizens enshrined in the Constitution which could come into confrontation.

Keywords: Journalism, Deontology, Law, Self Regulation, Responsability.
\end{abstract}

Referencia normalizada

SUÁREZ VILLEGAS, Juan Carlos (2013): "La complementariedad entre la deontología y el derecho a propósito de la actividad informativa". Estudios sobre el mensaje periodístico. Vol. 19, Núm. 1, págs.: 281-293. Madrid, Servicio de Publicaciones de la Universidad Complutense.

Sumario: 1. Introducción. 2. Desarrollo; 2.1. La ética profesional como punto de partida; 2.2. Razones para el autocontrol; 2.3. La Complementariedad entre deontología y derecho. 3. Conclusiones. 4. Referencias bibliográficas.

\section{Introducción}

En el ambiente inestable propio de una sociedad plural en constante mutación como en la que estamos insertos, la pertinencia de una serie de valores éticos configurados como guías para el desempeño de cualquier profesión se antoja indispensable si se pretende salvaguardar los bienes netamente humanos necesarios para la vida en sociedad (tales como la sanidad, la seguridad o la información). El desarrollo de estas guías éticas indisolubles a cualquier práctica sientan asimismo las bases de una correlación de códigos deontológicos desarrollados en el seno de cada profesión para su correcto funcionamiento, $\mathrm{y}$ enmarcados por un sistema normativo concebido para respetar los bienes que persigue su ejercicio.

En este sentido, la deontología tendría por objeto definir los deberes que garantizan los bienes humanos específicos que son administrados a través del ejercicio profesional. Dichos bienes podrían ser realizados de diversas maneras, pero resulta 
necesario concretar cuáles son las pautas a seguir por los profesionales como compromiso con la ciudadanía. El propósito de la deontología, como señala Augusto Hortal (2004: pp. 57-58), sería el de marcar unos mínimos obligatorios para todos, compartido en los mismos términos y que valga de criterio para exigirse mutuamente su cumplimiento.

"El bien es pluriforme; tiene muchas facetas. De ahí que no sea exigible a todos en todos sus aspectos. Por eso hacen falta normas. Ellas tratan de salvaguardar unos mínimos obligatorios para todos, compartidos por todos en los mismos términos y que a todos se debe aplicar con idénticos criterios. Sin normas, no hay universalidad ni igualdad en las exigencias; sin igualdad y universalidad en las cuestiones necesarias, la cooperación social consagra y legitima desigualdades y arbitrariedades. La deontología habla de lo que es vinculante para todos. De los espacios abiertos y plurales que quedan para el bien se ocupa la ética". (Hortal, A., 1994, pp. 57-58)

Por tanto, el propósito de la deontología consiste en establecer pautas a priori, a fin de garantizar que los bienes administrados no queden en entredicho por posibles actitudes desaprensivas que comprometan la diligencia como un valor fundamental del crédito social de la profesión. Estos bienes internos de la profesión no pueden quedar relegados a aquellos otros que conciernen a los beneficios personales que genera su ejercicio como el dinero o la fama, pues quienes anteponen estos a los derechos de los ciudadanos convierte la profesión al servicio de la lógica del mercado (Ruiz, 2008: 344 y ss), renunciando a los fines éticos y sociales que singulariza la naturaleza de cualquier profesión. (Cortina: 2004). En este sentido, resulta también pertinente la afirmación del profesor Augusto Hortal cuando señala:

“[...] Para que, efectivamente, la profesión sirva para lo que dice servir, no basta que las regulaciones deontológicas y los considerandos éticos sean correctos y plausibles en teoría; hay que tratar de garantizar en la práctica que se apliquen efectivamente en beneficio de un buen servicio profesionalizado; Distinguiendo eso de las proclamas que tan sólo tratan de proteger la imagen, los intereses y el status del colectivo profesional y de cada uno de sus miembros" (Hortal, 1994: 62)

El caso más paradigmático de esta realidad escurridiza es, quizás, el de la medicina, en el que sus profesionales están orientados por unos códigos deontológicos que determinan los procedimientos de sus prácticas cotidianas a partir de una reflexión ética previa tendente a ofrecer unos servicios o bienes consustanciales a la profesión. Aquí la relación entre deontología y derecho aparece establecida de forma fluida, sin grandes contradicciones o excesivos encorsetamientos que dificulten el ejercicio del profesional.

$\mathrm{Al}$ abordar estos asuntos en lo concerniente a la profesión periodística, los obstáculos suelen ser, por el contrario, más numerosos. Constituir un estatuto de normas deontológicas para el periodismo supone un complejo juego de equilibrio entre una discrecionalidad ética que tiende a agredir algunos de los bienes sociales inherentes a la profesión (como el derecho a la veracidad de la información), y un marco 
reglamentario que coarte la libertad de los periodistas en sus labores habituales. De forma recurrente, el debate se presenta como una confrontación entre dos aspectos antagónicos cuya conciliación es poco menos que irrealizable. Sin embargo, en el presente artículo se reflexiona acerca de la complementariedad entre la responsabilidad social del periodista y su respeto hacia una serie de preceptos deontológicos consensuados en el seno de la propia profesión; y el conjunto de disposiciones englobadas en el derecho a la información. (Barroso Asenjo y López Talavera, 1997)

En este sentido, deontología y Derecho se complementan en la labor de exigir responsabilidades a los profesionales en distintos niveles de obligatoriedad y de manera correlativa, actuando el Derecho como una garantía a la labor de autocontrol que debería producirse en ámbito de la propia profesión. Siguiendo esta línea, el profesor Marc Carrillo (1999) ha indicado que esta labor de autonormación y el posterior complemento de la norma jurídica constituyen las principales novedades del derecho a la información de los ciudadanos en los estados democráticos.

"La experiencia de los países democráticos desde 1945 permite afirmar que la defensa de la libertad no es sinónimo de intervención; la dimensión objetiva del derecho a la información no puede obviar la necesidad de regular determinados ámbitos del proceso de producción informativa, justamente para permitir un efectivo ejercicio del derecho fundamental en todas sus facetas. Seguramente, la mejor solución es la que promueve la intervención del poder público en aquello que sea imprescindible y remite inmediatamente el resto a la autorregulación de las partes; de hecho, la complementariedad entre la regulación pública a través de la ley y la normación privada, mediante los códigos deontológicos y los estatutos de redacción, constituye en la actualidad de la información en España una fórmula de indudable interés para la tutela de los derechos del emisor y del receptor de la información" (Carrillo, 1999: 114)

Efectivamente, una garantía "jurídica" para la libertad de expresión, aunque parezca paradójico, consiste en la autolimitación del legislador a la hora de regular la actividad informativa, pues como sigue indicado el profesor de la Pompeu Fabra:

"Ciertamente, la ley puede no ser suficiente a este respecto; más aún, es probable que no lo sea ni pretenda serlo y que espere al complemento que las diversas vías autorreguladoras puedan ofrecer -por ejemplo, a través de los estatutos de redacción o de los consejos de la información- para completar desde la iniciativa privada, el establecimiento de unas condiciones reguladoras que aseguren un mejor ejercicio del derecho a comunicar información y, en consecuencia, un marco más adecuado para la tutela de los derechos del público" (Carrillo, 1999: 113)

Otra cuestión colindante al debate sobre el autocontrol es la definición de la identidad del periodista. No tenemos tiempo para adentrarnos aquí en este asunto, pero resulta pertinente expresar la conveniencia pragmática de reconocer la función especial de quienes ejercen de manera profesional la labor de administrar el derecho de los ciudadanos a la información, como una posición institucionalizada dentro del sistema democrático. A nuestro juicio, dicha labor debería ser asumidas por quienes acrediten una formación específica en ciencias de la información y con una vinculación laboral 
y profesional con los medios de comunicación, sin perjuicio de que esta labor informativa pueda ser complementada con otros formatos que incluyan la participación ocasional de expertos, líderes de opinión o representantes sociales que contribuyan a fomentar la opinión pública. Esta definición del profesional del periodismo se nos antoja urgente para evitar confusionismos que sólo benefician al mercado y que constituye un deterioro irreparable para los derechos de los profesionales. Por ello, la puesta en marcha de mecanismos institucionales destinados al reconocimiento social del profesional de la información, como los colegios profesionales de periodistas, puede constituir una medida adecuada para fortalecer la identidad y el compromiso de los profesionales (REAL, E, 2005, 2006). Y es que la fuga de la libertad de expresión y el derecho a la información de los ciudadanos también pueden provenir de una ineficaz protección de los derechos de los profesionales en los medios de comunicación. Por motivos de pragmatismo resulta necesario definir quiénes son los agentes encargados de asumir la labor profesional de informar desde una posición socialmente protegida y con especiales responsabilidades, evitando así que el periodismo quede a merced de los vaivenes del mercado. Este modelo de periodismo profesional, no excluye que de manera alternativa ciudadanos privados puedan ejercer su derecho a informar a través de formatos electrónicos, siempre que no se confunda con la actividad del periodismo profesional.

A través de esta investigación esperamos mostrar la naturaleza de la deontología como una disciplina a caballo entre la ética y el Derecho, con la ventaja de reunir las virtudes que caracterizan a ambas: un sentido interno de la obligación y un referente de autoridad pública para todos quienes decidan ejercer la profesión, por razón del servicio social que prestan. Esta debe constituirse, pues, como la piedra de toque de un nuevo marco profesional auspiciado por el autocontrol o autorregulación de todos los actores implicados en un debate amplio y prologando que entienda el periodismo como una práctica social imbricada por multitud de nodos de interconexión. Con este propósito analizaremos las relaciones entre la ética, la deontología y los profesionales sobre la tesis que establece que entre la Deontología profesional y el Derecho existe una continuidad normativa que convierte ambos ámbitos en sucesivos y complementarios en relación con los derechos y obligaciones de los profesionales. Con este objetivo, hemos procedido a ofrecer una primera presentación de la esfera de la ética, la deontología y el Derecho como tres niveles que jalonan el ámbito de la normatividad referida a la actividad profesional.

\section{Desarrollo}

\subsection{La ética profesional como punto de partida}

Cualquier sistema normativo ha de ser interpretado en relación con los fines y valores que se persiguen proteger a través del mismo, erigiéndose estos como un horizonte crítico para denunciar las limitaciones o disfunciones que puedan detectarse en su aplicación a la realidad. Este tipo de "valores superiores" o éticos están implícitos en las normas estableciendo el sentido en que deben ser interpretadas y aplicadas. De este modo, la deontología y el derecho pueden concebirse como elementos en interacción constante de los cuales emanan criterios normativos orientados por una serie 
de valores que marcan sus objetivos y prioridades. Estos valores adquieren un carácter dinámico y están abiertos a la reflexión racional del bienestar humano. Este sería el sentido de "la ética".

La ética profesional permite entender la deontología desde un sentido más amplio y abierto para recuperar la potencialidad reflexiva desde los valores de la actividad, a fin de revisar posibles contradicciones que pudiera derivarse de disfunciones normativas. En el ámbito de la acción existe una continuidad entre la reflexión (ética) y la norma (criterio establecido), como si se tratase de un sistema de compuertas que regula su caudal reflexivo a fin de evitar que la dispersión deje sin efecto el bien humano que se contempla realizar, pero al mismo tiempo, con la posibilidad de abrirlo cuando éste no quede asegurado por interpretaciones excesivamente estrechas de las normas.

La profesión es una práctica institucionalizada para la defensa, atención y promoción a un determinado bien humano (convertido en derecho básico o fundamental de las personas), tales como la enseñanza, la salud, la justicia o la información, entre otros. Por tanto, su gestión no es una mera actividad privada sino una práctica cuyos efectos interesan a la ciudadanía, pues de la calidad de dichos servicios públicos dependerá el grado de satisfacción en la vida comunitaria. Por otro lado, en la práctica profesional hay que distinguir los bienes internos de la actividad, que son aquellos que los fundamenta y que constituyen su finalidad (el del periodismo es, por ejemplo, la información de la ciudadanía), de aquellos otros bienes externos que se derivan de su ejercicio y que reportan un beneficio social o económico al profesional (en el mismo caso podría ser la notoriedad pública o la influencia política). Por supuesto, ambos son pretendidos lícitamente por parte de quien desea hacer de una actividad profesional su modo de vida, pero no resulta conveniente olvidar el carácter esencial y prevalente de los bienes internos sobre aquellos otros externos. La profesionalidad se deteriora cuando los bienes externos, es decir, enriquecimiento económico, fama o poder, son buscados como el objeto principal en el ejercicio de la profesión, desencadenando una inversión en el orden de los bienes asociados al ejercicio profesional (Cortina, 2004)

El periodismo es una profesión en la medida que cumple la función de administrar el derecho de los ciudadanos a ser informados, el cual adquiere, además de su vertiente subjetiva, un valor institucional como pilar básico de la sociedad democrática. Al profesional del periodismo le corresponde, por tanto, emprender un ejercicio ético y comprometido de sus funciones ineludibles frente a la ciudadanía. Ahora bien, en una sociedad de mercado en la que la noticia ha devenido en un poderoso reclamo comercial imbricado con toda una serie de discursos políticos y económicos, el mayor obstáculo se halla en cómo exigir una conducta responsable y adecuada a los medios de comunicación (Ruiz, 2010)

En este contexto surge con fuerza el debate en torno a la hipotética regulación de las libertades informativas. Para algunos teóricos y profesionales se trata de una actividad que debería regularse legislativamente desde instancias externas, en cambio, para otros, debería corresponder a la propia profesión establecer criterios de autorregulación para resolver las controversias en el ámbito de las libertades informativas (Pares i Maicas, 2006; Núñez Encabo, 2011) 


\subsection{Razones para el autocontrol}

En primer lugar, es preciso indicar que en el presente artículo trabajaremos con una interpretación extensiva del concepto de autocontrol con el fin de abarcar también otras fórmulas de naturaleza híbrida o de co-regulación, ya que se realiza con el concurso de diferentes agentes sociales. Por tanto, se trataría más de vías de resolución extrajudiciales o bien con reconocimiento legal, pero con un amplio margen para una autonormación basado en el consenso entre las distintas partes. De este modo, aunque me referiré al concepto de autocontrol en lo sucesivo, resultaría conveniente entenderlo como cualquier mecanismo que se ponga en marcha por parte de la profesión o de la ciudadanía para que los medios de comunicación atestigüen el modo en el que administran sus derechos informativos.

En este sentido, resulta oportuno recordar el sentido atribuido a la ética de los medios de comunicación que planteaba la Resolución 1003 del Consejo de Europa sobre este particular. Aunque el eje fundamental de los Códigos Deontológicos debe ser el periodista, no puede ignorarse que la actividad informativa se ejerce a través de empresas informativas y, por tanto, además de los códigos deontológicos, se deben establecer acuerdos de naturaleza profesional entre medios de comunicación y sus profesionales. En esta línea hay que enmarcar el desarrollo de los estatutos de redacción como documentos que regulan la participación de los periodistas en las decisiones de la empresa editorial. El objetivo de estos documentos se cifra en garantizar la independencia "ética" del profesional y su compromiso con la ciudadanía, frente a las posibles presiones internas que pueda recibir por parte del medio. Uno de los retos más importante de la libertad de expresión en las sociedades occidentales, como ya señalara el profesor Núñez Encabo, consiste en preservar la libertad en el medio de comunicación, pues será aquí donde se produzcan los nuevos procesos de censura informativa y, en consecuencia, la fuga de la libertad de expresión. La autorregulación contribuiría a paliar la defensa de la autonomía profesional frente a las presiones internas como ante la posible intromisión de los poderes políticos.

Podríamos concluir, pues, que el ejercicio de la actividad periodística se ejerce a través de empresas informativas, por lo que los principios éticos para ser efectivos necesitan integrar de forma ineludible tanto a las empresas como a los editores, sean públicos o privados. Esta es una novedad importante del Código Europeo por la que se establece que los Códigos Deontológicos deberían vincularse con el periodismo o con los medios de comunicación desde una perspectiva más genérica, y no con el periodista, ya que el ejercicio de sus funciones se enmarca en un entorno empresarial que lo condiciona. De este modo, el código se concibe como un pacto de las distintas partes en las que se dotan tanto de derechos garantizados como deberes profesionales mutuos, de acuerdo con las responsabilidades que compete a todos como agentes sociales de la comunicación. De otra forma sería imposible alcanzar un equilibrio justo entre propietarios, editores y profesionales para participar en un proyecto informativo en el que cada uno atiende a diversos intereses que deben ser evaluados a la luz de los fines socioeconómicos de la empresa informativa.

Dentro de este marco, los acuerdos deontológicos para supervisar las nuevas responsabilidades que surjan en el ejercicio informativo pueden ser muy amplios, potenciando así una vía de co-regulación en la que deberían estar también presentes los 
ciudadanos. Esta es la idea que inspira al profesor Núñez Encabo a defender un máximo ético de autonormación frente a un mínimo jurídico que establezca los límites dentro de los cuales debe producirse dicha actividad. De otra forma, podría incurrirse en el riesgo, ya mencionado, de que la regulación jurídica produzca un efecto contraproducente para el propósito de asegurar una mayor libertad de expresión,

"Si los contenidos de la actividad periodística se intentasen garantizar principalmente a través de normas jurídicas el peligro es que se podría encorsetar, sofocar y obstaculizar la propia libertad de expresión a través de una rígida coacción exterior y de una tipificación exagerada de conductas y manifestaciones en que lo lícito o ilícito se encuentra a veces en fronteras muy difíciles de deslindar. Por tanto parece más adecuado establecer un control asumido desde el interior de los medios y que se ejerza como autocontrol ético. En definitiva en relación con el ejercicio del periodismo es preferible aplicar un máximo ético y un mínimo jurídico. Sin embargo esta solo será una solución válida a condición de que los compromisos y la responsabilidad ética se asuman públicamente porque la ética del periodismo debe concebirse como una ética social y publica ya que los medios de comunicación sean públicos o privados ejercen claramente una función pública que afecta al mismo tiempo a todos los ciudadanos" (Núñez Encabo, 1999: 161)

Las razones para defender esta idea de autorregulación son las siguientes:

1. El autocontrol es una garantía de la identidad del informador, distinguiéndola de otras imágenes distorsionadas por prácticas individuales contrarias al compromiso ético de la profesión. El autocontrol actúa como un filtro de autodepuración interna, evitando que el descrédito que se derive del comportamiento de algunos profesionales arrastre consigo al de la propia profesión. Se evita de este modo que el descrédito de un profesional afecte al valor social de la información como profesión, que constituye una institución fundamental de la sociedad democrática. Por eso, como la señalado el profesor Hugo Aznar, "La primera utilidad que conlleva la creación de un código deontológico es que supone el reconocimiento público de la dimensión ética de una profesión o una actividad" (Aznar, 1997: 127)

2. Conviene señalar un segundo beneficio de los códigos deontológicos, indicado también por el profesor Hugo Aznar, como un referente pedagógico de los valores de la profesión que contribuyen a desarrollar un justo sentido de la actividad profesional. De igual modo, la códigos tienen un carácter abierto y pueden ser revisados y modificados, con lo que podrán amoldarse de manera más adecuadas a las nuevas exigencias planteadas en el ejercicio de la profesión.

"En segundo lugar, la existencia de los códigos también hace posible el aprendizaje colectivo de la profesión, fruto de una progresiva acumulación de experiencias en ellos. En efecto, si la discusión crítica de los contenidos de los códigos se acumula mediante revisiones periódicas de su contenido, estaremos ante una cierta manifestación de la capacidad de una profesión de madurar y aprender colectivamente desde el punto de vista moral" (Aznar, 1997: 129)

Por un lado, el código deontológico ha de ser preciso a fin de evitar interpretaciones ambiguas e interesadas que den al traste con el propósito de establecer crite- 
rios claros y comunes en el ejercicio de la profesión. Por otro lado, por muy detallado que pudiera ser un código, no puede abarcar todas las cuestiones que puedan surgir en el ejercicio profesional. La solución no es rechazarlo por ineficaz. En este sentido, los periodistas han de tener una mente abierta, ser conscientes de que la autorregulación no se ciñe en exclusiva a la letra impresa, sino que se complementa con la conciencia colectiva de los que aceptan voluntariamente unos límites éticos. Así, el código se adapta a distintas situaciones. Así se logra elevar el listón de responsabilidad colectiva de la profesión y se habilita un mecanismo de crítica y reprobación para aquellos profesionales que puedan actuar en contra de los principios deontológicos. De esta manera se logra que la ética transite de la mera intencionalidad individual a un proyecto social que implemente las virtudes como cualidades públicas de la profesión como una institución social, la cual tiene una dignidad que debe quedar reflejada en el comportamiento de quienes se dedican a ella. La virtud, que podría ser llamada de manera más justa, competencia, se acredita por la presencia de las actitudes éticas del profesional en su modo de llevar a cabo la actividad profesional. Surge así una conciencia de "la profesión" como un referente de la identidad social de quienes la practican. El prestigio moral de una profesión sirve así como mecanismo de exclusión -o cuando menos de identificación- de aquellos individuos que sólo quieren sacar provecho de ella.

3. Este proyecto de autorregulación combatiría también otro de los males endémicos de la profesión periodística: el individualismo, el afán quijotesco de pensar que los problemas sólo afectan a terceros y no a uno mismo, capaz de batallar con molinos de vientos para distorsionar la realidad y ubicar el listón de lo profesional en su propia experiencia personal. Esta circunstancia favorece una mayor docilidad del profesional frente a las exigencias del medio, pues la carencia de un proyecto común de profesión les deja sin recursos para protegerse (CANEL, M.J., et al., 2000). Por eso, la deontología no es un mero instrumento ético sino también social de defensa de la profesión, pues como ellos mismo reconocen, el individualismo mina los valores de la profesión, tal y como se pone de manifiesto en el informe sobre la profesión en el País Vasco, lo cual estimamos que sería extensivo al resto de la geografía española:

"El individualismo del sector se manifiesta en el hecho constatado de que la productividad y la competitividad entre los medios prima sobre las directrices recogidas en los códigos. Un $64,5 \%$ de los encuestados considera elevado el escaso asociacionismo y la poca defensa de la profesión. Esto se debe, a su juicio, a que se trata de un sector en el que existe una alta competitividad, lo que genera que los periodistas que trabajan en los medios vean al resto, más que como compañeros, como competidores, de manera que el obtener primero la noticia o el reconocimiento de la empresa o el éxito profesional se anteponen a la solidaridad y a las posibles vías de colaboración y unión” (Zalbidea et al, 2010)

Para paliar estos males endémicos del periodismo como organización profesional estimo que la mejor vía es la de la co-regulación, ejercida a través de un Consejo de información en el que quedaría integrado tanto la profesión como la sociedad civil para dirimir las controversias que se plantean desde la deontología profesional. Este tipo de instrumento tendría efecto en la medida que vincule a todos los medios de co- 
municación y sea refrendado jurídicamente, dotando así de eficacia al proyecto de exigir una comunicación responsable con los derechos de la ciudadanía. Se trataría de un órgano con capacidad jurídica pero con una dinámica de actuación más ágil, flexible y próxima a la realidad de la profesión para atender los perjuicios causados tanto a los ciudadanos como a la propia profesión. Esta es la sugerencia que se desprende también de la Resolución 1003 sobre ética del periodismo del Consejo de Europa cuando señala en el punto 37 :

"Para la supervisión de la aplicación de estos principios, es necesario crear organismos o mecanismos de autocontrol, compuestos por editores, periodistas, asociaciones de usuarios de medios de comunicación, representantes del ámbito universitario y jueces que elaboren resoluciones sobre el respeto de los preceptos deontológicos para los periodistas, que los medios se encargarán de hacer públicas. Todo esto ayudará al ciudadano que tiene derecho a la información, a tener un juicio crítico sobre el trabajo del periodista y sobre su credibilidad" (Consejo de Europa, 1993)

En esta misma línea se expresa también el Borrador de Ley Orgánica de Garantía del Derecho a la Información de la ciudadanía que defiende la co-regulación como la vía en la que se cruzan los derechos de los ciudadanos con los derechos de los periodistas, por lo que un modelo de esta naturaleza produciría una defensa reforzada de los derechos de los periodistas como medida fundamental para la calidad del derecho de los ciudadanos a ser informados.

El prestigio de este tipo de autoridad, basado en su independencia y el buen criterio de sus resoluciones, constituye un aval suficiente para que goce de refrendo jurídico y que sus criterios sean adoptados con carácter obligatorio por los profesionales para así evitar la discrecionalidad con la que se interpreta por parte de los profesionales las pautas deontológicas. Sería, por tanto, una manera de esclarecer que la deontología, aunque surge de una perspectiva normativa horizontal, pues son los propios agentes profesionales y los ciudadanos quienes definen sus criterios, goza de la fuerza legal para hacerlo cumplir a quienes asumen dicha función social.

\subsection{La complementariedad entre deontología y Derecho}

En este capítulo partimos de una postura muy similar a la sostenida por el profesor Emmanuel Derieux acerca de la relación entre Derecho y deontología profesional:

"La ética o deontología periodística -¿estos términos son totalmente sinónimos?- ¿Juega algún papel en las interpretaciones, apreciaciones y decisiones del Tribunal Europeo? ¿Se rige por el derecho exclusivamente o también por referencia a tales principios éticos? ¿Puede el TEDH ser juez de ellos? ¿Qué relaciones (de equivalencia, contradicción, concurrencia, complementariedad, subsidiariedad...) mantienen entre sí el derecho y la deontología? ¿Son nociones alternativas, sustituibles o intercambiables? Sin duda es deseable que, con mucha frecuencia, el derecho se conforme con la ética; siempre que ésta represente una norma común, generalmente admitida, y no sea, por el contrario, expresión de límites o exigencias, no muy claras, impuestas por un grupo concreto para su único beneficio. En el respeto a la jerarquía de las normas, la deontología da lugar a reglas que, más o menos voluntariamente, una profesión se da a sí misma. Ellas no pueden estar en contradicción con el derecho. Pero 
¿debe ajustarse a éste, con el riesgo de multiplicar así las restricciones y limitaciones?. Los profesionales afectados ¿las aceptarán o adoptarán el riesgo?” (Derieux, s/f)

Se podría aseverar que el Derecho por vía jurisprudencial reconoce la deontología como un estado de normatividad más difuso pero que puede adquirir naturaleza de ley como referencia de aplicación de leyes cuya realidad remite a la propia práctica profesional, tales como la diligencia, o el respeto a la buena fe de sus destinatarios, por ejemplo. En consonancia con esta idea, el Derecho encuentra una limitación en el propio sentido de la actividad informativa, pues puede establecer condiciones para garantizar el valor social de la noticia, pero no puede llegar a definir qué debe ser entendido por noticia o cómo ésta deba ser tratada, tal y como ha establecido el Tribunal Europeo de Derechos Humanos. Así, cabría traer a colación la siguiente sugerencia del profesor Derieux:

"Como ya se ha indicado, el TEDH señala, en sus resoluciones, que no corresponde, «a los tribunales nacionales, sustituir a la prensa para decir que técnica de informar deben adoptar los periodistas» (TEDH, 23 septiembre 1994, Jersild c. Dinamarca, § $31 ; 20$ mayo 1999, Bladet Tromso et Stensaad, §63...) ni, más ampliamente, decir cuáles deben ser sus métodos de trabajo y sus reglas de buena conducta o práctica profesional, cuya formulación y apreciación pertenecen a la ética o deontología periodística. Sin embargo, al mismo tiempo afirma que, « en razón de los deberes y responsabilidades inherentes al ejercicio de la libertad de expresión, la garantía que el artículo $10 »$ Conv.EDH «ofrece a los periodistas [...] está subordinada a la condición de que los interesados [...] elaboren informaciones fiables y precisas en el respeto a la ética»o «a la deontología periodística» (Derieux, s/f)

A nuestro juicio, entre deontología y Derecho existe una actividad complementaria que se exige mutuamente. Cualquier profesión que se precie debe desarrollar un cuerpo doctrinal de su actividad como fundamento indisoluble de su identidad social. La deontología es necesaria para aquilatar la responsabilidad de los profesionales y establecer un marco de interpretación de la posterior labor jurisprudencial de los tribunales de justicia sobre su diligencia.

De hecho, el Tribunal Europeo de Derechos Humanos ha elaborado una prolífera doctrina sobre los derechos de información que remiten de manera directa a la función de la deontología profesional como instancia desde la que entender y resolver tales conflictos. De ahí que la deontología deba adquirir un carácter institucional que sirva como primera instancia para la reflexión sobre las diversas cuestiones que atañe al ejercicio de la profesión.

Por tanto, la alternativa de "más Derecho" en relación a las libertades informativas, no se debe producir por una mayor regulación jurídica, sino por un mayor refrendo del Derecho a fórmulas de autonormación que velen de manera más diligente por un correcto ejercicio del derecho a la información. Frente a la procelosa y lenta vía judicial, los mecanismos de corregulación podrían dar una respuesta más rápida y proporcionada con las circunstancias de cada caso, exigiendo a las partes afectadas acatar su resolución, así como al resto de agentes profesionales.

Esta alternativa de resolución de conflictos también permitirá abordar cuestiones que tendrían difícil encaje legal, pues se trata de abusos informativos que son más 
merecedores de la reprobación de la profesión que objeto de una sanción legal. Particularmente en este asunto son importantes el lenguaje, la utilización de términos insultantes o poco respetuosos, los efectos derivados por las intenciones comunicativas asociadas al discurso de la noticia o la perpetuación de estereotipos de los colectivos más desfavorecidos.

La responsabilidad de los medios de comunicación y profesionales de la comunicación no sólo atañe al incumplimiento de las pautas deontológicas o jurídicas, sino también al modo en que sus discursos favorecen o perjudican a los valores democráticos y los derechos de los ciudadanos. Por eso la deontología atañe también a los valores de la profesión que actúan como guía hermenéutica para la crítica social de los medios de comunicación.

En consecuencia, la deontología adquiere un valor jurídico en la medida en que desciende a un plano de la praxis profesional y de las dimensiones éticas que deben acompañar a su actividad. Por ello, insistimos en señalar que ambas forman parte de un continuo normativo que se debe contemplar al mismo tiempo para compensar el peso de la norma con las razones que asisten a cada caso de acuerdo con los cánones profesionales. La deontología se convierte en fuente del Derecho e incluso en algún tipo de regla jurídica para dirimir la aplicación de las normas en el ámbito de las libertades informativas. Este dato vendría refrendado por las sentencias del TEDH, sobre el artículo 10 del Convenio, que se refieren a la ética o a la deontología periodística considerada como una fuente del derecho o destinada a atenuar las consecuencias de éste- para apreciar el fundamento de la intervención de los jueces nacionales en el ejercicio de la libertad de expresión de los periodistas, y de la sanción que ha podido considerarse como un abuso, según indica el profesor Derieux. En este mismo sentido, el profesor de La Sorbona suscita una interesante reflexión sobre estas conexiones entre deontología y Derecho cuando indica:

“¿El TEDH hará deontología sin saberlo, quererlo o reconocerlo? ¿Por qué motivo? ¿No se convertiría de este modo la deontología en una fuente del derecho e incluso en regla del derecho? Si la ética periodística parece más suave, menos limitativa y restrictiva que la regla del derecho, ¿Cuál sería entonces el valor de éste? ¿No se encontraría reemplazado? $\mathrm{Si}$, por el contrario, la deontología se sobreañade al derecho, los profesionales, a quienes se imponen las nuevas obligaciones complementarias ¿no se verían desanimados de preocuparse de la deontología... en detrimento de su libertad, de su sentido de responsabilidad, de la calidad de las informaciones difundidas y del servicio debido al público? En cualquier caso, no hay mucho que obtener o esperar, sobre este punto, de la jurisprudencia del Tribunal Europeo, globalmente favorable a la libertad de expresión, y con una amplia tendencia a considerar que la injerencia de las autoridades nacionales (legisladores y jueces, e incluso de instituciones de deontología) en el ejercicio de esta libertad no es «necesaria en una sociedad democrática» (Derieux, s/f)

\section{Conclusiones}

1. El Derecho constituye un marco de mínimos, mientras que la deontología amplía este círculo de exigencias profesionales para asegurar un correcto ejercicio de la actividad. Entre la deontología y el Derecho existe una relación complementaria, pues 
la ética aplicada en el ámbito de la actividad profesional pretenden aportar criterios más flexibles y ágil para el desarrollo de los derechos de los ciudadanos.

2. El concepto de la obligación no debe quedar reducido únicamente al sentido jurídico de "la sanción". Sería absurdo que no exista obligación por no existir sanción. Este es un elemento que explica la disuasión de realizar un comportamiento, pero no la razón por la que debemos hacerlos. En la terminología del jurista inglés Hart, no es lo mismo "estar obligado" que sentirse "bajo una obligación". No es lo mismo estar bajo la amenaza de un ladrón que atender a la petición de ayuda de alguien en necesidad. Son dos modos diversos de referirse a la libertad humana. Por desgracia, el Derecho es visto más como un agente coactivo que como un agente moral. Ello depende en gran medida de la legitimidad social de sus leyes y sus sentencias. Por otro lado, la deontología podría ser un referente normativo más próximo a la práctica profesional y, por tanto, con mayor peso moral para los periodistas (Coca, 1997; Real, 2010).

3. La deontología profesional si bien se refiere de manera principal a las medidas adoptadas por la profesión, debería estar abierta y ser receptiva a las recomendaciones que desde distintas instituciones y asociaciones de la sociedad civil se puedan formular acerca del comportamiento de los medios de comunicación, asumiendo como parte de su corpus normativo aquellos que pudieran revestir especial interés para orientar la actividad profesional. Por tanto, la autonormación puede proceder de diferentes instancias sociales que en un diálogo horizontal con la profesión transmitan sus criterios sobre los posibles efectos de la actividad informativa sobre los colectivos sociales o circunstancia de especial sensibilidad para los derechos de los ciudadanos. Por eso, cabría decir que la autorregulación podría comprender también otras fórmulas más abiertas que admitan la integración de agentes sociales o especialistas que puedan ponderar los efectos de la comunicación social (Aznar, 2010)

\section{Referencias bibliográficas}

BARROSO ASENJO, Porfirio y LÓPEZ TALAVERA, María del Mar (1997): La libertad de expresión y sus limitaciones constitucionales. Madrid, Fragua.

AZNAR, Hugo (1997): "El debate en torno a la utilidad de los códigos deontológicos de periodismo". Anàlisi, 20, pp. 125-144.

AZNAR, Hugo (2010): "Por una teoría normativa de la comunicación a las alturas de los tiempos: ¿Más derecho, más política, más ética? (A propósito de la publicación de la agonía del cuarto poder de Carlos Ruiz)". Dilemata, no 3, pp. 77-94.

CANEL, María José (2000): Periodistas al descubierto. Retrato de los profesionales de la información. Madrid, Centro de Investigaciones Sociológicas.

CARRILLO, Marc (1999): "Derecho a la información, ley y auto-regulación", en SUÁREZ, Juan Carlos (ed., 1999): Medios de Comunicación y Autocontrol. Entre la ética y el Derecho. Sevilla, Mad, pp. 109-125.

COCA, César (1997): "Códigos éticos y deontológicos en el periodismo español". ZER, 56, pp. 107-128. 
CONSEJO DE EUROPA (COUNCIL OF EUROPE, 1993): Resolution 1003 on the ethics of journalism. Bruxelles, Parliamentary Assemble: http://assembly.coe.int //main.asp?link=http://assembly.coe.int/documents/adoptedtext/ta93/ERES1003.H TM

CORTINA, Adela (2004): "Ciudadanía activa en una sociedad mediática", en GOZÁLVEZ, V. (ed.): Ética de los medios. Una apuesta por una ciudadanía audiovisual. Barcelona, Gedisa.

DERIEUX, Emmanuel (s/f): "Las referencias a la deontología de los medios en la sentencia del Tribunal Europeo de los Derechos Humanos". Relaciones entre Derecho y deontología" (texto traducido por Ana Azurmendi. Inédito).

HORTAL, Augusto (2002): Ética general de las profesiones. Bilbao, Desclée De Brouwer.

NUÑEZ ENCABO, Manuel (1999): "Los requisitos para la existencia del autocontrol de los medios de comunicación: el código europeo de deontología del periodismo", en SUÁREZ, Juan Carlos (ed.): Medios de Comunicación y Autocontrol. Entre la ética y el Derecho. Sevilla, Mad, pp. 149-158.

NUÑEZ ENCABO, Manuel (2011): "Máximo ético y mínimo jurídico". Revista Periodistas (FAPE), $\mathrm{n}^{\circ}$ 26, Madrid.

PARES I MAICAS, Manuel (2006): "El autocontrol de la información". Cuadernos de Periodistas, $\mathrm{n}^{\circ}$ 6. Madrid.

REAL, Elena (2005), "Un intento por clarificar los actos propios del ejercicio periodístico", en Estudios sobre el Mensaje Periodístico, vol. 11. Madrid, Servicio de Publicaciones de la Universidad Complutense, pp. 129-151.

REAL, Elena (2006) "Periodistas sin identidad profesional: puntualizaciones al proyecto para un futuro Estatuto", en Ámbitos, 15. Sevilla, Departamento de Periodismo II - Facultad de Comunicación de la Universidad de Sevilla, pp. 333-361.

REAL, Elena (2010): "La autorregulación. Valoración de los códigos. Conocimiento de los mecanismos de autorregulación", en ALSIUS, Salvador y SALGADO, Francesc (eds.): La ética informativa vista por los ciudadanos. Contraste de opiniones entre los periodistas y el público. Barcelona, UOC.

RUIZ, Carlos (2008): La agonía del cuarto poder. Prensa contra democracia. Barcelona, Trípodos.

ZALBIDEA BENGOA, Begoña; PÉREZ FUENTES, Juan Carlos; LÓPEZ PÉREZ, Susana; URRUTIA IZAGUIRRE, Santiago (2010): "Importancia, utilidad y conocimiento de los códigos éticos del periodismo en Euskadi". Vivat Academia. $\mathrm{n}^{\circ}$ 113. Diciembre. http://www.ucm.es/info/vivataca/numeros/n113/DATOSS.htm 